\title{
Prognostic markers of survival after combined mitotane- and platinum-based chemotherapy in metastatic adrenocortical carcinoma
}

\author{
Pasqualino Malandrino, Abir Al Ghuzlan ${ }^{1}$, Marine Castaing ${ }^{2}$, \\ Jacques Young ${ }^{3}$, Bernard Caillou, Jean-Paul Travagli ${ }^{4}$, \\ Dominique Elias ${ }^{4}$, Thierry de Baere ${ }^{5}$, Clarisse Dromain ${ }^{5}$, \\ Angelo Paci ${ }^{6}$, Philippe Chanson ${ }^{3}$, Martin Schlumberger, \\ Sophie Leboulleux and Eric Baudin
}

\author{
Service de Médecine Nucléaire et de Cancérologie Endocrinienne, Institut Gustave-Roussy, Université Paris XI, 39 rue Camille \\ Desmoulins, 94805 Villejuif Cedex, France \\ ${ }^{1}$ Département d'Anatomo-Pathologie, Institut Gustave-Roussy, Université Paris XI, 94805 Villejuif Cedex, France \\ ${ }^{2}$ G.F. Ingrassia Department, Integrated Tumor Registry of Catania-Messina-Siracusa, Hygiene and Public Health, University of \\ Catania, 95123 Catania, Italy \\ ${ }^{3}$ Service d'Endocrinologie, Faculté de Médecine, Hôpital Kremlin-Bicêtre, Université Paris VII, 94805 Kremlin-Bicêtre Cedex, France \\ ${ }^{4}$ Département de Chirurgie, ${ }^{5}$ Département d'Imagerie and ${ }^{6}$ Département de Pharmacologie Clinique, Institut Gustave-Roussy, \\ Université Paris XI, 94805 Villejuif Cedex, France \\ (Correspondence should be addressed to E Baudin; Email: baudin@igr.fr)
}

\begin{abstract}
To progress in the stratification of the first-line therapeutic management of metastatic adrenocortical carcinoma (ACC), we searched for prognostic parameters of survival in patients treated with combined mitotane- and cisplatinum-based chemotherapy as first-line. We retrospectively studied prospectively collected parameters from 131 consecutive patients with metastatic ACC (44 with a tissue specimen available) treated at the Gustave Roussy Institute with mitotane- and platinum-based chemotherapy. Fifty-five patients with clinical, pathological, and morphological data available together with treatment characteristics including detailed follow-up were enrolled. Plasma mitotane levels and ERCC1 protein staining were analyzed. Response was analyzed according to RECIST criteria as well as overall survival (OS) from the start of cisplatinum-based chemotherapy. Parameters impacting on OS were evaluated by univariate analysis, and then analyzed by multivariate analysis. Using a landmark method, OS according to response to chemotherapy was analyzed. Objective response to combined mitotaneand cisplatinum-based chemotherapy was $27.3 \%$. Median OS was 1 year. In the univariate analysis, resection of the primary, time since diagnosis, mitotane monotherapy as single first-line treatment, number of affected organs, plasma mitotane above $14 \mathrm{mg} / \mathrm{l}$, and objective response were predictors of survival. In the multivariate analysis, mitotane level $\geq 14 \mathrm{mg} / \mathrm{l}$ and objective response to platinum-based chemotherapy were found to be independent predictors of survival $(P=0.03$ and $<0.001)$. Our study suggests a prognostic role for mitotane therapy and objective response to platinum-based chemotherapy.
\end{abstract}

Endocrine-Related Cancer (2010) 17 797-807

\section{Introduction}

Adrenocortical carcinoma (ACC) is one of the most aggressive solid tumors, as highlighted by a 5 -year survival rate of below $13 \%$ in patients with distant metastases (Icard et al. 2001, Berruti et al. 2005, Abiven et al. 2006, Assie et al. 2007, Fassnacht et al. 2009). 
In 2010, surgery is the only curative therapeutic modality in localized ACC (Allolio \& Fassnacht 2006). In case of inoperable ACC, mitotane combined with cisplatinum has been demonstrated to yield objective responses but their impact on survival is still debated (Gicquel et al. 1997, Allolio \& Fassnacht 2006, Phan 2007, Fareau et al. 2008, Veytsman et al. 2009). Multiagent chemotherapy combining platinum with doxorubicin-etoposide or streptozotocin has yielded the highest objective response rates (Khan et al. 2000, Berruti et al. 2005), and was the basis for the first international randomized FIRMACT trial (http://clinicaltrials.gov/ct2/show/NCT00094497). New agents based on the validation of new molecular targets (Barlaskar et al. 2009, Carden et al. 2009, Nakamura et al. 2009) but also better prediction of the activity of drugs that have long been used in ACC (Haak et al. 1994, Baudin et al. 2001, Olaussen et al. 2006, Ronchi et al. 2009) can be considered as urgently needed.

A plasma mitotane level above $14 \mathrm{mg} / \mathrm{l}$ but also ERCC1 staining has both been proposed as predictors of response to mitotane- or cisplatinum-based therapies respectively (Haak et al. 1994, Baudin et al. 2001, Ronchi et al. 2009). Indeed, ACC patients with an elevated serum mitotane level $(>14 \mathrm{mg} / \mathrm{l})$ have been reported to achieve a 55-66\% objective response rate versus no response when mitotane levels remained below 14 mg/l (Haak et al. 1994, Baudin et al. 2001). Recently, low ERCC1 expression, ERCC1 being a marker of the presence of a DNA repair complex within tumor cells, was shown to be associated with efficacy of cisplatinum therapy in several cancers including lung, ovarian, and colorectal cancer (Dabholkar et al. 1994, Shirota et al. 2001, Lord et al. 2002, Olaussen et al. 2006) but also ACC patients (Ronchi et al. 2009).

A retrospective analysis was undertaken in a population of patients with metastatic ACC treated with first-line mitotane- and platinum-based chemotherapy and followed up in a single tertiary care referral center with two main goals: first to search for prognostic markers, including objective response, of overall survival (OS) after combined mitotane- and cisplatinum-based chemotherapy and, second to confirm the interest of plasma mitotane level monitoring and ERCC1 staining. To this end, all recently individualized prognostic parameters in patients with ENSAT stages III and IV ACC were cautiously analyzed (Bukowski et al. 1993, Abraham et al. 2002, Berruti et al. 2005, Assie et al. 2007, Fassnacht et al. 2009, Ronchi et al. 2009).

\section{Materials and methods}

\section{Patients and combined mitotane- and platinum-based chemotherapy}

Patients with a diagnosis of ACC referred for treatment to the Gustave Roussy Institute from January 1993 to March 2007 were retrospectively screened. Inclusion criteria were as follows: 1) pathological review of ACC, including Weiss score evaluation, 2) unresectable European network for the study of adrenal tumors tumor-node-metastasis (ENSAT-TNM) stages III or IV disease, 3) at least one cycle of first-line platinumbased chemotherapy combined or not with mitotane therapy, 4) the entire follow-up at the Gustave Roussy Institute including plasma mitotane measurement and chest and abdominal computed tomography (CT) scan imaging evaluation before chemotherapy, and then every 2 months during chemotherapy and every 3-4 months thereafter.

For more than 15 years, patients with inoperable ACC in our institution have received mitotane as a single first-line therapeutic option with the aim of achieving a therapeutic plasmatic concentration of between 14 and $20 \mathrm{mg} / \mathrm{l}$, as previously reported (Baudin et al. 2001, Faggiano et al. 2006). Platinum-based chemotherapy was administered in case of disease progression under mitotane therapy or combined with mitotane in case of rapidly progressive disease before treatment or a bulky tumor burden (Schlumberger et al. 1991, Bonacci et al. 1998). The initial chemotherapy regimens and drug doses were as follows: cisplatin $100 \mathrm{mg} / \mathrm{m}^{2}$ in 1 or 3 days + etoposide $100 \mathrm{mg} / \mathrm{m}^{2}$, days $1-3$ every 4 weeks or carboplatin (according to the Calvert formula) + etoposide $100 \mathrm{mg} / \mathrm{m}^{2}$, days $1-3$, again every 4 weeks. Chemotherapy was maintained until disease progression, persistent nonhematological grades 3-4 toxicity or patient's refusal. Cycles were delayed or doses reduced if grades $2-4$ toxicity failed to resolve.

\section{Data collection}

The following parameters were recorded in all patients: gender, age, hormone secretion, defined as the presence or not of clinical symptoms related to steroid secretions, the type of hormonal secretion, ENSAT stage at chemotherapy initiation (Fassnacht et al. 2009), previous therapeutic options including primary surgery and completeness of surgical resection (R0, $\mathrm{R} 1 / 2$, and Rx), delay between diagnosis of ACC, and initiation of platinum-based therapy (median and cutoff at 6 months), Weiss score (median and cut-off at 6), mitotic count within the primary tumor (cut-off at 20 per 50 high-power field), number of diseased organs 
(cut-off at 2), mitotane monotherapy as single first-line treatment (yes or no), and plasma mitotane level at the time of initiation of platinum-based therapy (cut-off at $14 \mathrm{mg} / \mathrm{l})$. The number of cycles including full-dose cycles was also recorded. In addition, ERCC1 staining was performed in a subgroup of 44 patients including 33 patients with all collected data available as described in the section.

\section{Immunostaining for ERCC1 and microscopic analysis}

A tissue block was available for 44 patients (39 surgical samples and 5 biopsy specimens), and analyzed before chemotherapy initiation. The entire specimen was analyzed by an expert pathologist (A A G) blinded to clinical data. We used a standard protocol for immunostaining of samples. In brief, for epitope retrieval, specimens were exposed to $10 \mathrm{mM}$ citrate buffer ( $\mathrm{pH} \mathrm{6.0)}$ and heated for $20 \mathrm{~min}$ in a water bath. Tumor sections were incubated for $60 \mathrm{~min}$ with a monoclonal antibody raised against the full-length human ERCC1 protein at a 1:100 dilution (mouse, clone $8 \mathrm{~F} 1$, Neomarker, Lab Vision, Fremont, CA, USA). Antibody binding was detected using an ABC kit with NovaRED as the substrate (Vectastain Elite, Vector Laboratories, Burlingame, CA, USA) and Mayer's hematoxylin as the counterstain. Sections of normal tonsil tissues were included as external positive controls (Olaussen et al. 2006), and stromal cells surrounding the tumor served as internal positive controls. The investigator, who evaluated ERCC1 staining under a light microscope at a magnification of $400 \times$, recorded whether tumor or stromal cells expressed ERCC1. Only samples with positive ERCC1 staining in the nucleus were deemed positive. Staining intensity was graded on a scale of $0-3$ (with a higher number indicating a higher intensity and with endothelial cells used as a reference and assigned an intensity of 2). The percentage of positive tumor nuclei was estimated semiquantitatively for each specimen, and a proportion score was assigned ( 0 if $0 \%, 0.1$ if $1-9 \%, 0.5$ if $10-49 \%$, and 1.0 if $50 \%$ or more), as previously described (Olaussen et al. 2006). This proportion score was multiplied by the staining intensity of nuclei to obtain a final semiquantitative $H$-score. In accordance with the above-referenced publication, an $H$-score $>1$ was a priori chosen as the cut-off point for separating samples with high ERCC1 (ERCC1-high) or low ERCC1 (ERCC1-low) expression. ERCC1 staining intensity (ascribed as high if equal to 3 or low if below 3 ) was also analyzed in this study.

\section{Response evaluation}

A chest and abdominal CT with contrast agent injection were performed prospectively in all patients within 4 weeks before chemotherapy initiation and every 2 months during the course of treatment. Subsequently, a chest and abdominal CT were performed every 3-4 months during follow-up. In addition, a bone scan was regularly performed. The best response was defined according to RECIST criteria (Therasse et al. 2000) based on the sum of the longest diameters of target lesions, the recording of nontargeted lesions and an assessment of new lesions. Briefly, complete (CR) or partial (PR) response to platinum was defined as the disappearance of any detectable morphological disease or a decrease in tumor burden exceeding 30\% respectively; progressive disease was defined as a tumor burden increase exceeding $20 \%$ or the appearance of new lesions; otherwise, the tumor was classified as stable disease. All images were prospectively analyzed at the time of treatment, and reviewed for the present study by two investigators (P M and C D). A consensus was reached in all cases. The best response obtained under platinum therapy was recorded in all patients. The mitotane level was monitored in patients using the HPLC method, in our institution (Baudin et al. 2001) or more recently by PAREXEL $(r=0.98$ between both methods as assessed in 45 consecutive patients in 2007). The mitotane level at the time of the best tumor response was also recorded.

\section{Statistical analysis and landmark method}

The median and range are provided for quantitative data, whereas numbers and percentages are used for qualitative data. Percentages were compared using the $\chi^{2}$ test, and the $t$-test was used for continuous variables. November 1st, 2008 was the date of the last follow-up for the censored data analysis. The endpoint of our study was OS after the initiation of cisplatinum-based chemotherapy (time between cisplatinum initiation and death from any cause or the date of the last visit). Response to chemotherapy was analyzed through logistic regression, and the results are reported with the odds ratio and $95 \%$ confidence intervals (CI). OS was calculated using the Kaplan-Meier method (Kaplan \& Meier 1958) and Rothman's 95\% CI (Rothman 1978). All tests are two-sided. Univariate and multivariate analyses were performed using the logrank test and Cox models (Cox 1972). The results of the Cox model analysis are reported with relative risks and the $95 \% \mathrm{CI}$. Variables with a $P$ value below 0.1 were retained in the multivariate analyses. A landmark 
method (Simon 1989) was used to determine survival from 2 months after the initiation of therapy to provide an unbiased conditional estimate of the response and OS. In fact, the time origin is shifted to the right with this method, so that response can be considered as any other prognostic factor known at the origin of survival time. The level of significance chosen was the conventional 5\% (0.05). Statistical analyses were performed with the SAS software, version 9.1 (SAS_Institute 1999, SAS, Cary, NC, USA).

\section{Results}

\section{Clinical and therapeutic characterization of the population under study}

One hundred and thirty-one patients (46 males and 85 females) were seen during the study period (Table 1). After a careful appraisal of the clinical data collected, 76 were finally excluded: 10 patients did not fulfill the first inclusion criterion (pathological review of ACC), 14 patients did not fulfill the second inclusion criterion (unresectable ENSAT-TNM stages III or IV disease), 31 patients did not fulfill the third inclusion criterion (at least one cycle of first-line platinum-based chemotherapy combined or not with mitotane therapy), and 21 patients did not fulfill the fourth inclusion criterion (entire follow-up at the Gustave Roussy Institute including plasma mitotane measurement and imaging evaluation). Thus, 55 patients with ACC constituted the study population.

The main characteristics of the population under study compared with the excluded population are described in Table 1. In the 55 patients, platinum-based chemotherapy was given together with mitotane at the time of treatment initiation in 11 patients or administered in case of disease progression under mitotane therapy in 44 patients, including 15 patients with at least one plasma mitotane level above $14 \mathrm{mg} / \mathrm{l}$ within the month prior chemotherapy. Initially, 50 patients were given the cisplatinum regimen, and five patients were given the carboplatin regimen (see Materials and methods). In addition, 10 out of 50 patients first treated with cisplatinum, received carboplatin as second-line therapy due to cisplatinum-induced toxicity or to maintain or improve the tumor response after six cycles of cisplatinum therapy. The dose was reduced in nine patients, delayed in ten patients but never discontinued due to toxicity. Subsequently, various treatment options were administered including other chemotherapies (31 patients) and loco-regional therapy in 24 patients including surgery in four patients.
Table 1 Main characteristics of the whole population under study

\begin{tabular}{|c|c|c|c|}
\hline $\begin{array}{l}\text { Clinical } \\
\text { features }\end{array}$ & $\begin{array}{l}\text { Excluded } \\
\text { patients } \\
(n=76)\end{array}$ & $\begin{array}{l}\text { Patients } \\
\text { under study } \\
\quad(n=55)\end{array}$ & $\boldsymbol{P}$ \\
\hline \multicolumn{4}{|l|}{ Gender } \\
\hline Male & $31(40.8)$ & $15(27.3)$ & \multirow[t]{2}{*}{0.11} \\
\hline Female & $45(59.2)$ & $40(72.7)$ & \\
\hline $\begin{array}{l}\text { Age at first platinum } \\
\text { cycle (mean } \pm \text { s.D.) }\end{array}$ & $46.6 \pm 16.6$ & $45.2 \pm 14.4$ & 0.29 \\
\hline \multicolumn{4}{|l|}{ Hormonal secretion } \\
\hline No & $47(61.8)$ & $17(30.9)$ & \multirow[t]{2}{*}{$<0.001$} \\
\hline Yes & $29(38.2)$ & $38(69.1)$ & \\
\hline \multicolumn{4}{|l|}{ Type of secretion } \\
\hline Cortisol & $47(61.8)$ & $17(30.9)$ & \multirow[t]{4}{*}{0.09} \\
\hline Androgens & $18(23.7)$ & $17(30.9)$ & \\
\hline Aldosterone & $10(13.2)$ & $6(10.9)$ & \\
\hline Missing & $1(1.3)$ & $15(27.3)$ & \\
\hline \multicolumn{4}{|l|}{ Stage at diagnosis } \\
\hline $1-I I$ & $33(47.8)$ & $22(40.0)$ & \multirow[t]{3}{*}{0.38} \\
\hline III-IV & $36(52.2)$ & $33(60.0)$ & \\
\hline Missing & $7(9.2)$ & - & \\
\hline \multicolumn{4}{|c|}{ Surgical resection of primary tumor } \\
\hline No & $1(1.3)$ & $5(9.1)$ & \multirow[t]{3}{*}{0.09} \\
\hline Yes & $68(89.5)$ & $50(90.9)$ & \\
\hline Missing & $7(9.2)$ & - & \\
\hline \multicolumn{4}{|c|}{ Completeness of surgical resection } \\
\hline Ro & $39(51.3)$ & $24(43.6)$ & \multirow[t]{3}{*}{0.63} \\
\hline $\mathrm{R} 1-2$ & $30(39.5)$ & $26(47.3)$ & \\
\hline $\mathrm{Rx}$ & $7(9.2)$ & - & \\
\hline $\begin{array}{l}\text { Median delay between } \\
\text { diagnosis and meta- } \\
\text { static disease } \\
\text { (months; range) }\end{array}$ & $2.9(0-100.3)$ & $2.8(0-24.1)$ & 0.85 \\
\hline \multicolumn{4}{|c|}{ Delay between diagnosis and metastatic disease } \\
\hline$\leq 6$ months & $47(61.8)$ & $34(61.8)$ & \multirow[t]{2}{*}{0.99} \\
\hline$>6$ months & $29(38.2)$ & $21(38.2)$ & \\
\hline $\begin{array}{l}\text { Weiss score } \\
\text { (median, range) }\end{array}$ & $6(2-9)$ & $6(2-9)$ & 0.11 \\
\hline \multicolumn{4}{|l|}{ Weiss score $>6$} \\
\hline No & $30(39.5)$ & $26(47.3)$ & \multirow[t]{3}{*}{0.10} \\
\hline Yes & $13(17.1)$ & $23(41.8)$ & \\
\hline Missing & $33(43.4)$ & $6(10.9)$ & \\
\hline \multicolumn{4}{|l|}{ Mitotic count } \\
\hline$\leq 20$ & $39(51.3)$ & $35(63.6)$ & \multirow[t]{3}{*}{0.12} \\
\hline$>20$ & $12(15.8)$ & $20(36.4)$ & \\
\hline Missing & 25 (32.9) & - & \\
\hline \multicolumn{4}{|c|}{ Number of metastatic organs } \\
\hline$\leq 2$ & $68(89.5)$ & $40(72.7)$ & \multirow[t]{2}{*}{0.01} \\
\hline$>2$ & $8(10.5)$ & $15(27.3)$ & \\
\hline \multicolumn{4}{|l|}{ Mitotane $>14 \mathrm{mg} / \mathrm{l}$} \\
\hline No & $10(13.2)$ & $7(12.7)$ & \multirow[t]{3}{*}{0.98} \\
\hline Yes & $25(32.9)$ & $32(58.2)$ & \\
\hline Missing & $41(53.9)$ & $16(29.1)$ & \\
\hline $\begin{array}{l}\text { Total number of CDDP } \\
\text { cycles (median, } \\
\text { range) }\end{array}$ & $4(1-9)$ & $4(1-12)$ & 0.09 \\
\hline $\begin{array}{l}\text { Number of full-dose } \\
\text { CDDP cycles } \\
\text { (median, range) }\end{array}$ & $3.5(1-7)$ & $4(1-12)$ & $<0.0001$ \\
\hline
\end{tabular}

CDDP, cisplatin. 


\section{Cisplatinum-based chemotherapy: characterization of tumor responses}

A median number of four cycles was administered (range 1-12). A number of 18, 15, 16, and 6 patients received one or two cycles, three or four cycles, five or six cycles, and more than six cycles of platinum-based chemotherapy respectively. Fifteen out of 55 patients (27.3\%) achieved an objective response including 3 CR and 12 PR. CRs lasted 1 year, 1.4 years, and 5.7 years. PR lasted from 8.0 months to 14.4 months (median $=11.5$ months). Stabilization was observed in ten patients $(18.2 \%)$, lasting from 2.0 to 10.6 months (median $=4.8$ months). Progressive disease was found in the remaining $30 \mathrm{ACC}$ patients at the time of the first evaluation. During chemotherapy, all 55 patients were on mitotane. The mitotane level during response was available for 39 patients including 18 whose mitotane level was within the therapeutic range (14-20 mg/l).

\section{Overall survival}

At the time of the analysis, 50 patients had died, and five were still alive. Median disease-free interval between first treatment of the ACC and the diagnosis of metastasis was 2.8 months (range $=0-24.1$ ).

The median delay between diagnosis of ACC and platinum-based therapy was 11 months (range $=0.3-120.4$ months). The median delay between the diagnosis of metastasis and platinum-based therapy was 5 months (range $=0.2-120.4$ months).

Median OS after the initiation of cisplatinum-based chemotherapy was 1 year (range $=18$ days -11 years). OS was $>6$ months, 1 year, or 2 years in 42 (76.4\%), $27(49.1 \%)$, and 11 (20\%) patients respectively.

\section{Prognostic parameters for OS after initiation of mitotane- and platinum-based chemotherapy}

The parameters analyzed are described in the section data collection and in Table 2 (Fig. 1). In the univariate analysis, resection of the primary tumor (hazard ratio $(\mathrm{HR})=3.77,95 \% \mathrm{CI}=(1.39-10.2), P=0.009)$, the number of metastatic organs $(\mathrm{HR}=2.97,95 \%$ $\mathrm{CI}=(1.51-5.86), P=0.002)$, time between diagnosis of ACC and initiation of cisplatinum therapy $(\mathrm{HR}=0.52$, 95\% $\mathrm{CI}=(0.28-0.96), P=0.04)$, mitotane monotherapy as single first-line treatment $(\mathrm{HR}=0.42,95 \% \mathrm{CI}$ $=(0.21-0.84), P=0.014)$, plasma mitotane $>14 \mathrm{mg} / \mathrm{l}$ $(\mathrm{HR}=0.51,95 \% \mathrm{CI}=(0.25-1.05), P=0.07)$, and objective response to cisplatinum-based chemotherapy $(\mathrm{HR}=4.19,95 \% \mathrm{CI}=(1.99-8.83), P<0.0001)$ were predictive for OS. Median OS was 13.5 and 7.7 months in patients who underwent or not surgical resection of the primary tumor respectively. Median OS was 15.6 and 7.1 months in patients with fewer than 2 or 2 or, more than 2 diseased organs respectively. Median OS was 13.3 and 7.6 months in patients with a time interval between the diagnosis of ACC and initiation of cisplatinum of 6 or more months or below 6 months respectively. Median OS was 13.3 and 4.0 months respectively in patients who received mitotane therapy as a single first-line or not respectively. Median OS was 19.6 and 9.5 months for patients with a mitotane level $\geq 14$ and $<14 \mathrm{mg} / \mathrm{l}$ respectively (Fig. 1A). Lastly, median OS for responders to cisplatinumbased chemotherapy was 40.6 months, whereas it was 9.6 months in nonresponders (Fig. 1B). In the multivariate analysis, the objective response to cisplatinum-based chemotherapy $(\mathrm{HR}=5.55,95 \%$ $\mathrm{CI}=(2.06-14.96), P<0.001)$ and the mitotane level $\geq 14 \mathrm{mg} / \mathrm{l} \quad(\mathrm{HR}=0.35, \quad 95 \% \quad \mathrm{CI}=(0.14-0.89)$, $P=0.03)$ were found to be independent prognostic factors for survival after platinum-based chemotherapy (Table 2). According to the absence of the presence of one or two of these independent prognostic factors, median survival was 35.6 months for patients with none of them, and 19.7 months and 7.1 months for patients with one or two respectively (log-rank $P$ value for trend $<0.0001$; Fig. 1C).

\section{ERCC1 expression in ACC}

Among the 44 patients in whom the ERCC1 $H$-score was analyzed, 21 (47\%) had an $H$-score below 1 . The characteristics of ACC patients with a low ERCC1 $H$-score (ERCC1-low) compared with a high ERCC1 $H$-score (ERCC1-high) are described in Table 3. No major differences were observed between patients with a high or low ERCC1 $H$-score. Thirty-three of these 44 patients fulfilled inclusion criteria: 3 out of 18 patients $(16.7 \%)$ with ERCC1-high and 4 out of 15 patients (26.7\%) with ERCC1-low achieved an objective response $(P=0.48)$. Median $O S$ in ERCC1-low patients was 13.3 months, and median OS in ERCC1-high patients was 10.1 months (not significant). The same analysis taking into account ERCC1 staining intensity showed that an objective response was observed in 1 out of 11 patients (9.1\%) expressing a high-intensity staining score of 3 and in 6 out 22 patients $(27.3 \%)$ expressing a lowintensity staining score of $<3$. Median OS in patients with ERCC1-low intensity was 14.5 months and 7.6 months in patients with ERCC1-high intensity (not significant). 
Table 2 Univariate and multivariate associations between clinic-demographic factors and overall survival

\begin{tabular}{|c|c|c|c|c|}
\hline Clinical features & $\begin{array}{l}\text { Univariate analysis } \\
(\mathrm{OR} ; 95 \% \mathrm{Cl})\end{array}$ & $\boldsymbol{P}$ & $\begin{array}{l}\text { Multivariate analysis } \\
(\mathrm{OR} ; 95 \% \mathrm{Cl})\end{array}$ & $\boldsymbol{P}$ \\
\hline \multicolumn{5}{|l|}{ Gender } \\
\hline Male $(n=15)$ & 1 & & & \\
\hline Female $(n=40)$ & $0.69(0.37-1.29)$ & 0.25 & & \\
\hline \multicolumn{5}{|l|}{ Age at first platinum cycle } \\
\hline$<44.5$ years $(n=28)$ & 1 & & & \\
\hline$\geq 44.5$ years $(n=27)$ & $1.14(0.64-2.03)$ & 0.66 & & \\
\hline \multicolumn{5}{|l|}{ Hormonal secretion } \\
\hline No $(n=17)$ & 1 & & & \\
\hline Yes $(n=38)$ & $1.19(0.63-2.22)$ & 0.59 & & \\
\hline \multicolumn{5}{|l|}{ Stage at diagnosis } \\
\hline $\mathrm{I}-\mathrm{II}(n=22)$ & 1 & & & \\
\hline III-IV $(n=33)$ & $1.22(0.69-2.18)$ & 0.50 & & \\
\hline \multicolumn{5}{|c|}{ Surgical resection of primary tumor } \\
\hline Yes $(n=50)$ & 1 & & & \\
\hline No $(n=5)$ & $3.77(1.39-10.20)$ & 0.009 & & \\
\hline \multicolumn{5}{|l|}{ Completeness of surgical resection } \\
\hline $\mathrm{RO}(n=29)$ & 1 & & & \\
\hline $\mathrm{R} 1-2(n=26)$ & $1.34(0.75-2.39)$ & 0.32 & & \\
\hline \multicolumn{5}{|l|}{ Weiss score } \\
\hline$\leq 6(n=26)$ & 1 & & & \\
\hline$>6(n=23)$ & $0.83(0.45-1.52)$ & 0.54 & & \\
\hline \multicolumn{5}{|l|}{ Mitotic count } \\
\hline$\leq 20(n=35)$ & 1 & & & \\
\hline$>20(n=20)$ & $0.81(0.44-1.48)$ & 0.48 & & \\
\hline \multicolumn{5}{|l|}{ Number of metastatic organs } \\
\hline$\leq 2(n=40)$ & 1 & & 1 & \\
\hline$>2(n=15)$ & $2.97(1.51-5.86)$ & 0.002 & $1.65(0.53-5.15)$ & 0.39 \\
\hline \multicolumn{5}{|l|}{ Mitotane $>14 \mathrm{mg} / \mathrm{l}$} \\
\hline No $(n=7)$ & 1 & & 1 & \\
\hline Yes $(n=32)$ & $0.51(0.25-1.05)$ & 0.07 & $0.35(0.14-0.89)$ & 0.03 \\
\hline \multicolumn{5}{|l|}{ ERCC1 $\mathrm{H}$-score ${ }^{\mathrm{a}}$} \\
\hline$\leq 1(n=15)$ & - & & & \\
\hline \multicolumn{5}{|l|}{$>1(n=18)$} \\
\hline \multicolumn{5}{|l|}{ ERCC1 staining intensity } \\
\hline$<3(n=22)$ & 1 & & & \\
\hline $3(n=11)$ & $1.37(0.63-2.94)$ & 0.43 & & \\
\hline \multicolumn{5}{|c|}{ Delay between diagnosis of ACC and initiation of CDDP } \\
\hline$\leq 6(n=15)$ & 1 & & & \\
\hline$>6$ months $(n=40)$ & $0.52(0.28-0.96)$ & 0.04 & & \\
\hline \multicolumn{5}{|c|}{ Mitotane monotherapy as single first-line treatment } \\
\hline No $(n=11)$ & 1 & & 1 & \\
\hline Yes $(n=44)$ & $0.42(0.21-0.84)$ & 0.014 & $0.61(0.17-2.32)$ & 0.48 \\
\hline \multicolumn{5}{|l|}{ Response $^{\mathrm{b}}$} \\
\hline Objective $(n=15)$ & 1 & & 1 & \\
\hline Stable or progression $(n=33)$ & 4.19 (1.99-8.83) & $<0.0001$ & $5.55(2.06-14.96)$ & $<0.001$ \\
\hline
\end{tabular}

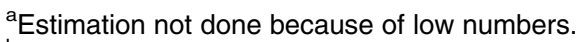

${ }^{\mathrm{b}}$ In agreement with the landmark method, patients who die ( $\left.n=7 \mathrm{pts}\right)$ before the landmark time point were excluded, making a total number of 48 patients available for statistical analysis.

\section{Discussion}

Progress in the field of ACC has generally been considered limited over the recent decades because the magic bullet targeting the magic target is still awaited. This should not however overlook the fact that progress has been made in the definition of prognostic parameters of $\mathrm{ACC}$ and in predictors of response
(Haak et al. 1994, Baudin et al. 2001, Stojadinovic et al. 2002, Berruti et al. 2005, Abiven et al. 2006, Assie et al. 2007, Fassnacht et al. 2009). Prognostic studies enable the evaluation of various strategies in homogeneous prognostic subgroups of ACC patients. The latter set of data allows one to tailor therapeutic options to a given tumor in a given patient. 

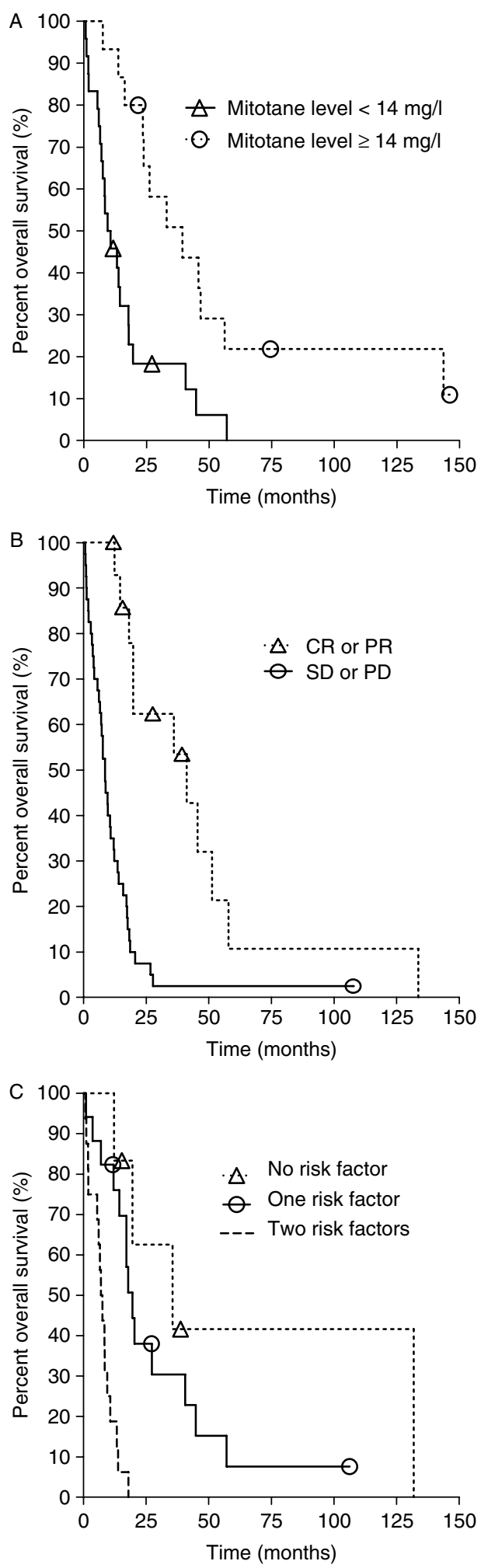

Figure 1 Overall survival as a function of mitotane level $(A)$, objective response $(B)$, and the absence or the presence of one or two of these factors (C). CR, complete response; PR, partial response; $S D$, stable disease; $P D$, progressive disease. Open circles and triangles indicate censored subjects.
Finally, the first randomized study ever conducted has been set up, indicating the involvement of networks in this rare cancer.

In the field of cytotoxic chemotherapy, apart from mitotane therapy, cisplatinum is considered the drug of choice but is certainly not efficient enough. In this study, combined first-line therapy with mitotane- and cisplatinum-based chemotherapy allowed a $27 \%$ objective response rate, which is in the range of previous reports (van Slooten et al. 1984, Schlumberger et al. 1991, Bukowski et al. 1993, Berruti et al. 1998, Bonacci et al. 1998, Williamson et al. 2000, Abraham et al. 2002). Owing to the combination with mitotane therapy in most studies, the exact antitumor role of cisplatinum-based chemotherapy remains uncertain. In addition, the delayed activity of mitotane skewed a proper analysis of the antitumor role of other drugs (Veytsman et al. 2009).

To the best of our knowledge, four published studies have pursued a similar objective, which was to highlight prognostic parameters of ACC patients at the time of chemotherapy initiation (Bukowski et al. 1993, Abraham et al. 2002, Berruti et al. 2005, Ronchi et al. 2009). In addition, one study previously analyzed prognostic parameters of stage IV ACC patients at the time of metastatic disease discovery (Assie et al. 2007). We found surgery of the primary, number of metastatic organs, time between diagnosis of ACC and cisplatinum initiation, mitotane monotherapy as single first-line treatment, plasma mitotane level above $14 \mathrm{mg} / \mathrm{l}$, and an objective response to chemotherapy to provide with the most powerful prognostic information. The two latter parameters remained significant at multivariate analysis. As a general consideration, whether parameters highlighted in our studies should be considered as prognostic parameters or predictors of response cannot be drawn from our study, and awaits further validation in randomized studies.

Although rarely investigated in previous studies, the prognostic impact of the resection of the primary has also been retrieved in two previous studies (Bukowski et al. 1993, Icard et al. 2001). This finding suggests a role for primary related local morbidity and therefore a role for primary surgery even in selected metastatic ACC patients. However, the fact that only five patients did not undergo primary surgery in our study precludes a definite conclusion. In contrast, the $R$ status seems to play a minor role in our study in contrast with recent data (Abraham et al. 2002, Bilimoria et al. 2008). One explanation could be that the prognostic role of the $R$ status may be mainly related to potentially curable stages I-II ACC patients. Our study confirms a prognostic role of the number of diseased organs at 
Table 3 Characteristics of the whole population of adrenocortical carcinoma (ACC) patients according to ERCC1 immunostaining

\begin{tabular}{|c|c|c|c|}
\hline $\begin{array}{l}\text { Clinical } \\
\text { features }\end{array}$ & $\begin{array}{l}\text { ERCC1-high } \\
\quad(n=23)\end{array}$ & $\begin{array}{l}\text { ERCC1-low } \\
\quad(n=21)\end{array}$ & $\boldsymbol{P}$ \\
\hline \multicolumn{4}{|l|}{ Gender } \\
\hline Male & 7 (30.4) & $6(28.6)$ & 0.89 \\
\hline Female & $16(69.6)$ & $15(71.4)$ & \\
\hline $\begin{array}{l}\text { Age at first platinum } \\
\text { cycle (mean } \pm \text { s.D.) }\end{array}$ & $49.0 \pm 15.0$ & $39.0 \pm 14.5$ & 0.88 \\
\hline \multicolumn{4}{|l|}{ Hormonal secretion } \\
\hline No & $11(47.8)$ & $9(42.9)$ & 0.74 \\
\hline Yes & $12(52.2)$ & $12(57.1)$ & \\
\hline \multicolumn{4}{|l|}{ Type of secretion } \\
\hline Cortisol & $6(26.1)$ & $1(4.8)$ & 0.25 \\
\hline Androgens & $11(47.8)$ & $9(42.9)$ & \\
\hline Aldosterone & $4(17.4)$ & 7 (33.3) & \\
\hline Missing & $2(8.7)$ & $4(19.1)$ & \\
\hline \multicolumn{4}{|l|}{ Stage at diagnosis } \\
\hline $\mathrm{I}-\mathrm{II}$ & $10(43.5)$ & $6(28.6)$ & 0.30 \\
\hline III-IV & $13(56.5)$ & $15(71.4)$ & \\
\hline \multicolumn{4}{|c|}{ Surgical resection of primary tumor } \\
\hline No & $3(13.0)$ & $2(9.5)$ & - \\
\hline Yes & $20(87.0)$ & $19(90.5)$ & \\
\hline \multicolumn{4}{|c|}{ Completeness of surgical resection } \\
\hline Ro & $13(56.5)$ & 7 (33.3) & 0.14 \\
\hline $\mathrm{R} 1-2$ & $10(43.5)$ & $14(66.7)$ & \\
\hline \multicolumn{4}{|c|}{ Delay between diagnosis of $\mathrm{ACC}$ and initiation of CDDP ${ }^{\mathrm{a}}$} \\
\hline$\leq 6$ months & $6(33.3)$ & $5(33.3)$ & - \\
\hline$>6$ months & $12(66.7)$ & $10(66.7)$ & \\
\hline $\begin{array}{l}\text { Weiss score } \\
\text { (median, range) }\end{array}$ & $6(2-9)$ & $6(2-9)$ & 0.38 \\
\hline \multicolumn{4}{|l|}{ Weiss score > 6} \\
\hline No & $10(43.5)$ & $13(33.3)$ & 0.55 \\
\hline Yes & $8(34.8)$ & 7 (61.9) & \\
\hline Missing & $5(21.7)$ & $1(4.8)$ & \\
\hline \multicolumn{4}{|l|}{ Mitotic count } \\
\hline$\leq 20$ & $14(60.9)$ & $16(76.2)$ & 0.28 \\
\hline$>20$ & $9(39.1)$ & $5(23.8)$ & \\
\hline \multicolumn{4}{|c|}{ Number of metastatic organs } \\
\hline$\leq 2$ & $17(73.9)$ & $16(76.2)$ & - \\
\hline$>2$ & $6(26.1)$ & $5(23.8)$ & \\
\hline \multicolumn{4}{|l|}{ Mitotane $>14 \mathrm{mg} / \mathrm{l}$} \\
\hline No & $4(17.4)$ & 7 (33.3) & 0.47 \\
\hline Yes & $14(60.9)$ & $11(52.4)$ & \\
\hline Missing & $5(21.7)$ & $3(14.3)$ & \\
\hline $\begin{array}{l}\text { Total number of } \\
\text { CDDP cycles } \\
\text { (median, range) }\end{array}$ & $4(1-6)$ & $3(1-12)$ & 0.66 \\
\hline $\begin{array}{l}\text { Number of full-dose } \\
\text { CDDP cycles } \\
\text { (median, range) }\end{array}$ & $4(1-6)$ & $3.5(1-12)$ & 0.96 \\
\hline
\end{tabular}

${ }^{a}$ Analysis done on 33 patients receiving platinum-based chemotherapy.

the time of chemotherapy initiation, as highlighted in two prognostic studies performed in unresectable stages III-IV ACC (Berruti et al. 2005, Assie et al. 2007). Together, these results suggest that tumor burden at the time of chemotherapy initiation could be a critical parameter. A higher survival rate was found in patients with time between diagnosis of ACC and initiation of cisplatinum longer than 6 months, as already found by other teams (Berruti et al. 2005). This parameter may simply reflect a lower aggressiveness of the disease but also that this first-line chemotherapy is not active in rapidly progressive disease. The absence of prognostic information related to high mitotic index may be interpreted in the same way.

A prognostic impact of mitotane therapy in metastatic ACC patients has been suggested by several prognostic studies (Icard et al. 2001, Kendrick et al. 2001, Abiven et al. 2006) but not all (Venkatesh et al. 1989). In addition, the prognostic influence of plasma mitotane levels above $14 \mathrm{mg} / \mathrm{l}$ has been previously reported in two studies (Haak et al. 1994, Wangberg et al. 2010) but not in all (Abraham et al. 2002). Our study reinforces the role of mitotane therapy in ACC patients when plasma level above $14 \mathrm{mg} / \mathrm{l}$ can be reached. Interestingly, responses were observed in patients with progressive disease even in those who did or did not experience at least one plasma level above $14 \mathrm{mg} / \mathrm{l}$ prior chemotherapy initiation. This result may suggest either an impact of combined platinum-based chemotherapy or, the need for prolonged period of high plasma level of mitotane to achieve antitumor effect. With respect to this comment, the understanding of the prognostic influence of mitotane therapy started as first-line at univariate analysis is not straightforward. Such strategy may confer a greater chance to rapidly achieve therapeutic plasma level of mitotane hampering cumulative digestive toxicity of both mitotane and cytotoxic chemotherapy. An alternative hypothesis could be that this parameter identifies a subgroup of patients with lower aggressiveness allowing time to initiate mitotane therapy. In the absence of randomized trial to solve this issue, we advocate to maintain mitotane therapy as long as the tolerance is acceptable until at least two plasma levels above $14 \mathrm{mg} / \mathrm{l}, 2$ months apart, are reached.

We confirm the prognostic impact of chemotherapyrelated objective response, as previously suggested (Abraham et al. 2002, Berruti et al. 2005, Gonzalez et al. 2007). Objective response was the most significantly correlated parameter with OS: a remarkable median OS of 40.6 months was observed in patients experiencing an objective response. This OS is clearly longer than the 10-28 months median OS reported in previous studies (Decker \& Kuehner 1991, Bukowski et al. 1993, Williamson et al. 2000, Abraham et al. 2002, Berruti et al. 2005) suggesting a survival benefit of therapy in this subgroup of ACC patients. Since for the first time all individualized 
prognostic parameters and predictors of response individualized to date were included in the statistical analysis, we hypothesize that biases related to confounding prognostic parameters are decreased. Objective response to combined mitotane- and platinum-based chemotherapy may therefore be considered as a surrogate marker for survival in ACC patients, and this has to be confirmed in future randomized studies. Finally, these results suggest that ACC patients in whom therapeutic mitotane plasma level above $14 \mathrm{mg} / \mathrm{l}$ cannot be attained or in whom objective response is not achieved within the initial phase of therapy should be proposed alternative therapeutic strategy.

Recently, using tissue microarray analysis, Ronchi et al. were the first to report that ERCC1 staining was the strongest predictor of survival after the initiation of cisplatinum in 45 ACC patients. In that study, low staining for ERCC1 was indicative of a higher response rate observed in $29 \%$ of ACC patients versus $14 \%$ when ERCC1 staining was high, with the most significant impact on survival. Using the same methodology, we found a similar response rate $(26.7$ vs $16.7 \%$ in ERCC1-low and -high patients respectively) but ERCC1 staining had no influence on survival after platinum-based chemotherapy. Multiple reasons may explain these discrepancies, the most important being that one cannot predict whether a tumor response in ACC is due to cisplatinum-based chemotherapy alone or combined with mitotane therapy. These discrepancies may also be related to the lower number of cases analyzed in our series. However, our study includes additional data like the measurement of plasma mitotane level in the vast majority of patients, RECIST review, and internal quality control for ERCC1 staining, which may also affect the general conclusion. One cannot exclude the possibility that other methodological approach for ERCC1 analysis or other molecular partners involved in DNA repair might be interfering (Siddik 2003).

In conclusion, in metastatic ACC patients, in the absence of an established treatment protocol, combined mitotane- and cisplatinum-based chemotherapy could be considered an acceptable first-line treatment option if plasma mitotane level above $14 \mathrm{mg} / \mathrm{l}$ is obtained and or an objective response demonstrated within the initial phase of treatment.

\section{Declaration of interest}

The authors declare that there is no conflict of interest that could be perceived as prejudicing the impartiality of the research reported.

\section{Funding}

This research did not receive any specific grant from any funding agency in the public, commercial or not-for-profit sector.

\section{Author contribution statement}

We are indebted to the nurses of the Nuclear Medicine Department. We thank Lorna Saint Ange for editing.

\section{References}

Abiven G, Coste J, Groussin L, Anract P, Tissier F, Legmann P, Dousset B, Bertagna X \& Bertherat J 2006 Clinical and biological features in the prognosis of adrenocortical cancer: poor outcome of cortisol-secreting tumors in a series of 202 consecutive patients. Journal of Clinical Endocrinology and Metabolism 91 2650-2655. (doi:10. 1210/jc.2005-2730)

Abraham J, Bakke S, Rutt A, Meadows B, Merino M, Alexander R, Schrump D, Bartlett D, Choyke P, Robey R et al. 2002 A phase II trial of combination chemotherapy and surgical resection for the treatment of metastatic adrenocortical carcinoma: continuous infusion doxorubicin, vincristine, and etoposide with daily mitotane as a P-glycoprotein antagonist. Cancer 94 2333-2343. (doi:10.1002/cncr.10487)

Allolio B \& Fassnacht M 2006 Clinical review: adrenocortical carcinoma: clinical update. Journal of Clinical Endocrinology and Metabolism 91 2027-2037. (doi:10. 1210/jc.2005-2639)

Assie G, Antoni G, Tissier F, Caillou B, Abiven G, Gicquel C, Leboulleux S, Travagli JP, Dromain C, Bertagna X et al. 2007 Prognostic parameters of metastatic adrenocortical carcinoma. Journal of Clinical Endocrinology and Metabolism 92 148-154. (doi:10.1210/jc.2006-0706)

Barlaskar FM, Spalding AC, Heaton JH, Kuick R, Kim AC, Thomas DG, Giordano TJ, Ben-Josef E \& Hammer GD 2009 Preclinical targeting of the type I insulin-like growth factor receptor in adrenocortical carcinoma. Journal of Clinical Endocrinology and Metabolism 94 204-212. (doi:10.1210/jc.2008-1456)

Baudin E, Pellegriti G, Bonnay M, Penfornis A, Laplanche A, Vassal G \& Schlumberger M 2001 Impact of monitoring plasma 1,1-dichlorodiphenildichloroethane (o, $\left.p^{\prime} \mathrm{DDD}\right)$ levels on the treatment of patients with adrenocortical carcinoma. Cancer 92 1385-1392. (doi:10.1002/1097-0142 (20010915)92:6<1385::AID-CNCR1461>3.0.CO;2-2)

Berruti A, Terzolo M, Pia A, Angeli A \& Dogliotti L 1998 Mitotane associated with etoposide, doxorubicin, and cisplatin in the treatment of advanced adrenocortical carcinoma, Italian Group for the Study of Adrenal Cancer. Cancer 83 2194-2200. (doi:10.1002/(SICI)1097-0142 (19981115)83:10<2194::AID-CNCR19>3.3.CO;2-V)

Berruti A, Terzolo M, Sperone P, Pia A, Casa SD, Gross DJ, Carnaghi C, Casali P, Porpiglia F, Mantero F et al. 2005 Etoposide, doxorubicin and cisplatin plus mitotane in the 
treatment of advanced adrenocortical carcinoma: a large prospective phase II trial. Endocrine-Related Cancer 12 657-666. (doi:10.1677/erc.1.01025)

Bilimoria KY, Shen WT, Elaraj D, Bentrem DJ, Winchester DJ, Kebebew E \& Sturgeon C 2008 Adrenocortical carcinoma in the United States: treatment utilization and prognostic factors. Cancer 113 3130-3136. (doi:10.1002/ cncr.23886)

Bonacci R, Gigliotti A, Baudin E, Wion-Barbot N, Emy P, Bonnay M, Cailleux AF, Nakib I \& Schlumberger M 1998 Cytotoxic therapy with etoposide and cisplatin in advanced adrenocortical carcinoma. British Journal of Cancer 78 546-549.

Bukowski RM, Wolfe M, Levine HS, Crawford DE, Stephens RL, Gaynor E \& Harker WG 1993 Phase II trial of mitotane and cisplatin in patients with adrenal carcinoma: a Southwest Oncology Group Study. Journal of Clinical Oncology 11 161-165.

Carden CP, Frentzas S, Langham M, Casamayor I, Stephens AW, Poondru S, Wheaton J, Lippman SM, Kaye SB \& Kim ES 2009 Preliminary activity in adrenocortical tumor (ACC) in phase I dose escalation study of intermittent oral dosing of OSI-906, a small-molecule insulin-like growth factor-1 receptor (IGF-1R) tyrosine kinase inhibitor in patients with advanced solid tumors. Journal of Clinical Oncology 27 (Supplement 15S) abstract 3544.

Cox D 1972 Regression models and life tables. Journal of the Royal Statistical Society 34 187-220.

Dabholkar M, Vionnet J, Bostick-Bruton F, Yu JJ \& Reed E 1994 Messenger RNA levels of XPAC and ERCC1 in ovarian cancer tissue correlate with response to platinumbased chemotherapy. Journal of Clinical Investigation 94 703-708. (doi:10.1172/JCI117388)

Decker RA \& Kuehner ME 1991 Adrenocortical carcinoma. American Surgeon 57 502-513.

Faggiano A, Leboulleux S, Young J, Schlumberger M \& Baudin E 2006 Rapidly progressing high $o, p^{\prime} \mathrm{DDD}$ doses shorten the time required to reach the therapeutic threshold with an acceptable tolerance: preliminary results. Clinical Endocrinology 64 110-113. (doi:10.1111/j.1365-2265. 2005.02403.x)

Fareau GG, Lopez A, Stava C \& Vassilopoulou-Sellin R 2008 Systemic chemotherapy for adrenocortical carcinoma: comparative responses to conventional first-line therapies. Anticancer Drugs 19 637-644. (doi:10.1097/CAD. 0b013e328300542a)

Fassnacht M, Johanssen S, Quinkler M, Bucsky P, Willenberg HS, Beuschlein F, Terzolo M, Mueller HH, Hahner S \& Allolio B 2009 Limited prognostic value of the 2004 International Union Against Cancer staging classification for adrenocortical carcinoma: proposal for a Revised TNM Classification. Cancer 115 243-250. (doi:10.1002/cncr.24030)

Gicquel C, Baudin E, Lebouc Y \& Schlumberger M 1997 Adrenocortical carcinoma. Annals of Oncology 8 423-427. (doi:10.1023/A:1008257530919)
Gonzalez RJ, Tamm EP, Ng C, Phan AT, VassilopoulouSellin R, Perrier ND, Evans DB \& Lee JE 2007 Response to mitotane predicts outcome in patients with recurrent adrenal cortical carcinoma. Surgery 142 867-875 (discussion 867-875). (doi:10.1016/j.surg.2007.09.006)

Haak HR, Hermans J, van de Velde CJ, Lentjes EG, Goslings BM, Fleuren GJ \& Krans HM 1994 Optimal treatment of adrenocortical carcinoma with mitotane: results in a consecutive series of 96 patients. British Journal of Cancer 69 947-951.

Icard P, Goudet P, Charpenay C, Andreassian B, Carnaille B, Chapuis Y, Cougard P, Henry JF \& Proye C 2001 Adrenocortical carcinomas: surgical trends and results of a 253-patient series from the French Association of Endocrine Surgeons Study Group. World Journal of Surgery 25 891-897. (doi:10.1007/s00268-001-0047-y)

Kaplan EL \& Meier P 1958 Non parametric estimation from incomplete observations. Journal of the American Statistical Association 53 457-481. (doi:10.2307/ 2281868)

Kendrick ML, Lloyd R, Erickson L, Farley DR, Grant CS, Thompson GB, Rowland C, Young WF Jr \& van Heerden JA 2001 Adrenocortical carcinoma: surgical progress or status quo? Archives of Surgery 136 543-549. (doi:10. 1001/archsurg.136.5.543)

Khan TS, Imam H, Juhlin C, Skogseid B, Grondal S, Tibblin S, Wilander E, Öberg K \& Eriksson B 2000 Streptozocin and $o, p^{\prime} \mathrm{DDD}$ in the treatment of adrenocortical cancer patients: long-term survival in its adjuvant use. Annals of Oncology 11 1281-1287. (doi:10.1023/A:1008377915129)

Lord RV, Brabender J, Gandara D, Alberola V, Camps C, Domine M, Cardenal F, Sanchez JM, Gumerlock PH, Taron M et al. 2002 Low ERCC1 expression correlates with prolonged survival after cisplatin plus gemcitabine chemotherapy in non-small cell lung cancer. Clinical Cancer Research 8 2286-2291.

Nakamura M, Miki Y, Akahira J, Morimoto R, Satoh F, Ishidoya S, Arai Y, Suzuki T, Hayashi Y \& Sasano H 2009 An analysis of potential surrogate markers of targetspecific therapy in archival materials of adrenocortical carcinoma. Endocrine Pathology 20 17-23. (doi:10.1007/ s12022-009-9058-2)

Olaussen KA, Dunant A, Fouret P, Brambilla E, André F, Haddad V, Taranchon E, Filipits M, Pirker R, Popper HH et al. 2006 DNA repair by ERCC1 in non-small-cell lung cancer and cisplatin-based adjuvant chemotherapy. New England Journal of Medicine 355 983-991. (doi:10.1056/NEJMoa060570)

Phan AT 2007 Adrenal cortical carcinoma - review of current knowledge and treatment practices. Hematology/ Oncology Clinics of North America 21 489-507 (viii-ix). (doi:10.1016/j.hoc.2007.04.007)

Ronchi C, Sbiera S, Kraus L, Wortmann S, Johanssen S, Adam P, Willenberg H, Hahner S, Allolio B \& Fassnacht M 2009 Expression of excision repair cross complementing group 1 and prognosis in adrenocortical carcinoma 
patients treated with platinum-based chemotherapy. Endocrine-Related Cancer 16 907-908. (doi:10.1677/ ERC-08-0224)

Rothman KJ 1978 Estimation of confidence limits for the cumulative probability of survival in life table analysis. Journal of Chronic Diseases 31 557-560. (doi:10.1016/ 0021-9681(78)90043-7)

SAS_Institute Inc. 1999 SAS User's Guide, Version 9. Cary, NC: SAS Institute, Inc.

Schlumberger M, Brugieres L, Gicquel C, Travagli JP, Droz JP \& Parmentier C 1991 5-Fluorouracil, doxorubicin, and cisplatin as treatment for adrenal cortical carcinoma. Cancer 67 2997-3000. (doi:10.1002/1097-0142(19910615) 67:12<2997::AID-CNCR2820671211>3.0.CO;2-\#)

Shirota Y, Stoehlmacher J, Brabender J, Xiong YP, Uetake H, Danenberg KD, Groshen S, Tsao-Wei DD, Danenberg PV \& Lenz HJ 2001 ERCC1 and thymidylate synthase mRNA levels predict survival for colorectal cancer patients receiving combination oxaliplatin and fluorouracil chemotherapy. Journal of Clinical Oncology 19 4298-4304.

Siddik ZH 2003 Cisplatin: mode of cytotoxic action and molecular basis of resistance. Oncogene 22 7265-7279. (doi:10.1038/sj.onc.1206933)

Simon R 1989 Optimal two-stage designs for phase II clinical trials. Controlled Clinical Trials 10 1-10. (doi:10.1016/ 0197-2456(89)90015-9)

van Slooten H, Moolenaar AJ, van Seters AP \& Smeenk D 1984 The treatment of adrenocortical carcinoma with $o, p^{\prime}$-DDD: prognostic implications of serum level monitoring. European Journal of Cancer and Clinical Oncology 20 47-53. (doi:10.1016/0277-5379(84)90033-6)

Stojadinovic A, Ghossein RA, Hoos A, Nissan A, Marshall D, Dudas M, Cordon-Cardo C, Jaques DP \& Brennan MF
2002 Adrenocortical carcinoma: clinical, morphologic, and molecular characterization. Journal of Clinical Oncology 20 941-950. (doi:10.1200/JCO.20.4.941)

Therasse P, Arbuck SG, Eisenhauer EA, Wanders J, Kaplan RS, Rubinstein L, Verweij J, Van Glabbeke M, van Oosterom AT, Christian MC et al. 2000 New guidelines to evaluate the response to treatment in solid tumors. European Organization for Research and Treatment of Cancer, National Cancer Institute of the United States, National Cancer Institute of Canada. Journal of the National Cancer Institute 92 205-216. (doi:10.1093/jnci/92.3.205)

Venkatesh S, Hickey RC, Sellin RV, Fernandez JF \& Samaan NA 1989 Adrenal cortical carcinoma. Cancer 64 765-769. (doi:10.1002/1097-0142(19890801)64:3< 765::AID-CNCR2820640333>3.0.CO;2-I)

Veytsman I, Nieman L \& Fojo T 2009 Management of endocrine manifestations and the use of mitotane as a chemotherapeutic agent for adrenocortical carcinoma. Journal of Clinical Oncology 27 4619-4629. (doi:10. 1200/JCO.2008.17.2775)

Wangberg B, Khorram-Manesh A, Jansson S, Nilsson B, Nilsson O, Jakobsson CE, Lindstedt S, Oden A \& Ahlman H 2010 The long-term survival in adrenocortical carcinoma with active surgical management and use of monitored mitotane. Endocrine-Related Cancer 17 265-272. (doi:10.1677/ERC-09-0190)

Williamson SK, Lew D, Miller GJ, Balcerzak SP, Baker LH \& Crawford ED 2000 Phase II evaluation of cisplatin and etoposide followed by mitotane at disease progression in patients with locally advanced or metastatic adrenocortical carcinoma: a Southwest Oncology Group Study. Cancer 88 1159-1165. (doi:10.1002/(SICI)1097-0142(20000301) 88:5<1159::AID-CNCR28> 3.0.CO;2-R) 